\title{
Two new Geranomyia Haliday (Diptera, Limoniidae) crane flies from Mount Jiulong in China, with an updated key to Chinese species
}

\author{
Xingyang Qian', Xiao Zhang' \\ I Key Lab of Integrated Crop Pest Management of Shandong Province, College of Plant Health and Medicine, \\ Qingdao Agricultural University, Qingdao 266109, China \\ Corresponding author: Xiao Zhang (xzhang_cn@163.com)
}

Academic editor: Netta Dorchin | Received 20 December 2019 | Accepted 26 June 2020 | Published 27 July 2020

http://zoobank.org/0AA9A04B-AA0A-4FE3-896D-07BBC005373D

Citation: Qian X, Zhang X (2020) Two new Geranomyia Haliday (Diptera, Limoniidae) crane flies from Mount Jiulong in China, with an updated key to Chinese species. ZooKeys 953: 105-118. https://doi.org/10.3897/zookeys.953.49557

\begin{abstract}
The genus Geranomyia Haliday, 1833 is globally distributed, with 351 known species, of which 26 occur in China. Herein, an overview of the genus Geranomyia from Mount Jiulong, Zhejiang, China, is presented. Two new species are described and illustrated. Geranomyia jiulongensis sp. nov. and G. subablusa sp. nov. are distinguished from other Geranomyia species by the characters of the thorax and male genitalia. An updated key to the Geranomyia of China is presented.
\end{abstract}

\section{Keywords}

crane fly, Limoniinae, Limoniini, classification, new species, Zhejiang

\section{Introduction}

Geranomyia Haliday, 1833 is a large genus of 351 described species in the family Limoniidae. It is characterized by the following characters: body small or medium-sized (5-9 $\mathrm{mm}$ ), flagellum with 12 segments, elongate mouthparts, $R_{1+2}$ present, $R_{2}$ commonly present, $R_{4}$ and $R_{5}$ fused to margin, only two branches of Rs present as longitudinal elements $\left(R_{3}\right.$ and $\left.R_{4+5}\right)$, two branches of $M$ reaching wing margin, and lobe of gonostylus often with two spines (Alexander 1967a; Haliday 1833; Osten Sacken 1869). 
The adults of Geranomyia species were often found sucking nectar from flowers (Alexander 1948, 1967b; Zhang et al. 2016). Some phenological studies have shown that adults have a long period of activity; for example, adults of $G$. canadensis (Westwood, 1836) were active from April to September, G. communis Osten Sacken, 1860 from May to October, and G. rostrata (Say, 1823) from April to September (Young 1978; Young and Gelhaus 2000). The habitats of adult flies have been rather frequently discussed in the literature (Alexander 1916, 1919, 1920, 1928a, 1928b, 1948, 1964, 1970a; Englund 1999; Harrison and Barnard 1972; Knab 1910). Geranomyia advena (Alexander, 1954) has been found around seeps and adjacent to riffle habitats in streams on Molokai and Hawaii (Englund 1999). The type of G. annandalei Edwards, 1913 was collected on the Plain of Gennesaret, near the Sea of Galilee, where it was found on limestone cliffs overhanging a spring (Alexander 1970b).

The habitats of the immature stages have also been extensively investigated. The larvae of $G$. canadensis was found living on the faces of rock exposures, crawling among algae and diatoms (Alexander and Malloch 1920). Rogers (1927) found the immature stages of $G$. rostrata living in wet moss, among the thalli of liverworts and in mats of filamentous algae on wet rocks and shaded seepage areas. Bangerter (1929) found the larvae of G. caloptera Mik, 1867 living among saturated mosses on wet banks of streams. The immature stages of $G$. diversa Osten Sacken, 1860 was found in and beneath thick mats of dripping algae on wet, shaded cliffs (Rogers 1930). Geranomyia argentifera de Meijere, 1911 and G. fletcheri Edwards, 1911 have habitats that are generally similar to the above-mentioned species (Alexander1931).

Twenty-six species of Geranomyia have been previously recorded from China (Oosterbroek 2020), of which five were published by Zhang et al. (2016). Since that publication, further new materials of the genus have become available. Mount Jiulong is located in southwestern Zhejiang, China, with a total area of $200 \mathrm{~km}^{2}$. The main peak is $1,724 \mathrm{~m}$ high, which is the fourth highest peak in Zhejiang. The area includes more than $6 \mathrm{~km}^{2}$ of virgin, typically subtropical, broad-leaf forest. Mount Jiulong is reputed to be a "Biological Gene Pool", with more than 1,340 species of plants and 149 species of vertebrates. This investigation into Geranomyia species on Mount Jiulong, Zhejiang, China, was initiated by the authors together with other entomologists from Zhejiang A\&F University in July 2019, and four species of Geranomyia were found. In this paper, two new species are described and illustrated, and two known Chinese species are also listed. A dichotomous key to the Chinese species of Geranomyia is modified from Zhang et al. (2016) and updated with additional diagnostic characters.

\section{Materials and methods}

Specimens for this study were collected on Mount Jiulong, Zhejiang, China, in July 2019 by the authors. Adult crane flies were collected by insect net and at artificial light. Genitalic preparations of males were made by macerating the apical portion of the abdomen in cold $10 \% \mathrm{NaOH}$ for $12-15$ hours. Observations and illustra- 
tions were made using a ZEISS Stemi 2000-C stereomicroscope. Photographs were taken with a Canon EOS 77D digital camera through a macro lens. Type specimens of known Chinese species deposited in the National Museum of Natural History, Smithsonian Institution, Washington, DC, USA (USNM), the Natural History Museum, London, UK (NHM) and the Entomological Museum of China Agricultural University, Beijing, China (CAU) were examined. Type specimens of the new species were deposited in the Entomological Museum of Qingdao Agricultural University, Shandong, China (QAU).

The morphological terminology mainly follows McAlpine (1981), and the venation is described after Alexander and Byers (1981). Terminology of the male hypopygium follows Ribeiro (2006). The following abbreviations are used: $\operatorname{tg} 9=$ ninth tergite, $\operatorname{tg} 10=$ tenth tergite, goncx $=$ gonocoxite, $\mathrm{c}$ gonst $=$ clasper of gonostylus, 1 gonst $=$ lobe of gonostylus, aed $=$ aedeagus, $\mathrm{pm}=$ paramere, cerc $=$ cercus, hyp vlv $=$ hypogynial valve, $\mathrm{mm}=$ millimeter .

\section{Taxonomy}

\section{Key to Chinese Geranomyia}

$1 \quad$ Wing patterned with dark brown stigma only ....................................... 2

- Wing patterned with many spots besides stigma (Figs. 1d, 3d) ..................6

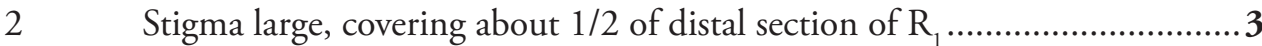

- $\quad$ Stigma small, covering about $1 / 3$ of distal section of $\mathrm{R}_{1} \ldots \ldots \ldots \ldots \ldots \ldots \ldots \ldots \ldots \ldots . . . . .14$

3 Prescutum with three confluent stripes; ovipositor with tip of hypogynial valve near $1 / 2$ way along cercus

G. contrita (Alexander, 1937) (Guangdong)

- $\quad$ Prescutum without stripes; ovipositor with tip of hypogynial valve near 3/4 way along cercus... G. nigra Zhang, Zhang \& Yang, 2016 (Gansu, Sichuan, Zhejiang, Guanxi, Yunnan, Taiwan)

4 Wing with basal section of $\mathrm{CuA}_{1}$ at fork of $\mathrm{M}$

G. nitida de Meijere, 1911 (Taiwan; Indonesia)

- Wing with basal section of $\mathrm{CuA}_{1}$ more than $1 / 3$ of its own length before (Figs 1d, 3d) or beyond fork of $\mathrm{M}$........................................................... 5

5 Wing with basal section of $\mathrm{CuA}_{1}$ about $3 / 4$ of its length beyond fork of $\mathrm{M}$; lobe of gonostylus with two short spines directly arising from rostral prolongation .............. G. argentifera (Taiwan, Hainan; Indonesia; Philippines) Wing with basal section of $\mathrm{CuA}_{1}$ about $1 / 3$ of its length before fork of $\mathrm{M}$; lobe of gonostylus with two long spines arising from a tubercle on rostral prolongation

G. gracilispinosa (Alexander, 1937) (Guangdong; India; Sri Lanka) Wing with spots in costal region except stigma small and weak; seams along cord, $\mathrm{m}-\mathrm{m}$ and basal section of $\mathrm{M}_{3}$ almost invisible

- Wing with spots in costal region large and dark; seams along cord, $\mathrm{m}-\mathrm{m}$ and basal section of $\mathrm{M}_{3}$ conspicuous (Figs 1d, 3d) 
Prescutum with two stripes G. atrostriata Edwards, 1921 (Taiwan)

- $\quad$ Prescutum with three stripes 8

Wing with a few distinct spots at base of $\mathrm{R}$

G. montana de Meijere, 1911 (Taiwan; Indonesia)

- Wing without conspicuous spot at base of R

... G. sparsiguttata (Alexander, 1937) (Chongqing, Sichuan, Fujian, Yunnan) Wing with basal section of $\mathrm{CuA}_{1}$ more than $1 / 3$ of its own length before fork of M (Figs 1d, 3d)

Wing with basal section of $\mathrm{CuA}_{1}$ less than $1 / 4$ of its length before or beyond fork of $M$

Lobe of gonostylus with two conspicuous tubercles on rostral prolongation (Fig. 2a)

Lobe of gonostylus with one or no tubercle on rostral prolongation (Fig. 4a)

11 Prescutum with a narrow brown median stripe; lobe of gonostylus small and short, slightly exceeding clasper of gonostylus

G. radialis (Alexander, 1930) (Zhejiang, Guangxi, Taiwan; Japan) Prescutum with three broad, dark-brown stripes (Fig. 1c); lobe of gonostylus large and long, more than twice length of clasper of gonostylus (Fig. 2a)

G. jiulongensis sp. nov. (Zhejiang)

12 Lobe of gonostylus with two long and slender spines, one arising from a large tubercle on rostral prolongation, other one directly arising from rostral prolongation (Fig. 4a)

13 Wing with spot at fork of Rs restricted under $\mathrm{Sc}$, cell $\mathrm{r}_{3}$ without spot under $\mathrm{R}_{2}$; lobe of gonostylus with two spines at tip and base of rostral prolongation respectively; distal part of paramere finger-shaped, lateral margin serrated or jagged

...G. tenuispinosa (Alexander, 1929) (Zhejiang, Fujian, Guangdong, Jiangxi) Wing with spot at fork of Rs covering Sc and reaching costal margin, cell $r_{3}$ with a spot under $\mathrm{R}_{2}$ (Fig. 3d); lobe of gonostylus with two spines at tip and middle of rostral prolongation respectively; distal part of paramere trianglar, lateral margin smooth (Fig. 4a)

14 Wing with a large spot at middle area of cell cua

G. maculata Zhang, Zhang \& Yang, 2016 (Taiwan)

Wing without conspicuous spot at middle area of cell cua

15 Pleuron of thorax without stripe; spot between first and second large spots in costal region very faint; lobe of gonostylus with rostral prolongation pointed at apex, middle of rostral prolongation with two subequal spines.

G. obesistyla (Alexander, 1940) (Sichuan)

- $\quad$ Pleuron of thorax with an ill-defined longitudinal stripe; spot between first and second large spots in costal region conspicuous; lobe of gonostylus with rostral prolongation blunt, middle of rostral prolongation with two spines, outer spine a little longer than inner spine .... G. suensoniana (Alexander, 1929) (Zhejiang) 
16 Wing with $\mathrm{Sc}_{1}$ ending at about $1 / 2$ to $2 / 3$ of Rs ...................................17

17 Wing with spots on origin of Rs and fork of Sc confluent in cell C or nearly so G. alpestris (Alexander, 1930) (Taiwan)

8 Wing with many small dots near $\mathrm{M}$ and CuA.....

..G. pictorum (Alexander, 1929) (Taiwan; India)

19 Prescutum with three broad longitudinal stripes

G. baisensis Zhang, Zhang \& Yang, 2016 (Guangxi)

Prescutum without evident markings.

G. spectata (Alexander, 1937) (Guangdong)

20 Wing heavily patterned, a large spot throughout wing tip, spot on origin of Rs posteriorly bifurcated

G. apicifasciata (Alexander, 1930) (Guangdong, Yunnan, Taiwan)

21 Wing without conspicuous spot at base

G. kiangsiana (Alexander, 1937) (Jiangxi)

22 Prescutum with a median longitudinal stripe

G. unifilosa (Alexander, 1934) (Taiwan)

Prescutum with three longitudinal stripes

23 Legs uniformly light brownish ... G. septemnotata Edwards, 1916 (Taiwan) Legs pale yellow to brownish yellow, with tibiae and tarsi darker, or femora with tips darker or bases paler .24

Costal region of wing with a small spot in cell $\mathrm{C}$ between second and third large spots.

G. fremida (Alexander, 1937) (Guangdong)

Costal region of wing without conspicuous spot in cell $\mathrm{C}$ between second and third large spots .25

Lobe of gonostylus with two spines.

..G. subradialis (Alexander, 1937) (Guangdong)

- Lobe of gonostylus with one spine

26 Lobe of gonostylus with rostral prolongation small, a very long and slender spine arising from a tubercle on rostral prolongation

\section{G. longispina Zhang, Zhang \& Yang, 2016 (Fujian)}

- Lobe of gonostylus with rostral prolongation long and slender, a long and powerful spine directly arising from rostral prolongation

Male hypopygium with posterior margin of tergite nine deeply and narrowly notched; clasper of gonostylus small, slender, and nearly straight.....

G. bifurcula (Alexander, 1933) (Sichuan)

- $\quad$ Male hypopygium with posterior margin of tergite nine emarginate; clasper of gonostylus absent. 


\section{Geranomyia jiulongensis sp. nov.}

http://zoobank.org/2E46B202-AA91-4C18-9421-6355DE078719

Figures 1, 2

Diagnosis. Prescutum yellow with three broad, dark-brown longitudinal stripes. Pleuron of thorax yellow, with a broad, dark-brown stripe. Wing with seven large spots on costal region; $\mathrm{Sc}_{1}$ ending near fork of $\mathrm{Rs}$, basal section of $\mathrm{CuA}_{1}$ nearly its length before fork of M. Lobe of gonostylus large with an arched rostral prolongation armed with two basal spines arising from two tubercles.

Description. Male. Body length 5.0-5.3 mm, wing length $5.3-5.5 \mathrm{~mm}$, mouthparts length 2.2-2.3 $\mathrm{mm}$.

Head (Fig. 1b). Black. Setae on head black. Antenna length 1.2-1.3 mm, brownish black. Scape cylindrical. Pedicel nearly globose. Flagellomeres oval, terminal flagellomere with tip knob-like. Mouthparts brownish black with black setae.

Thorax (Fig. 1c). Pronotum yellow with a broad dark brown median stripe. Prescutum yellow, with three broad, dark-brown longitudinal stripes, each lateral stripe about $1 / 2$ length of median stripe. Scutum pale yellow, with a dark-brown longitudinal stripe at middle area, each lobe with a large, dark-brown spot. Scutellum yellow, with two sides and anterior region dark brown, posterior region with a dark-brown spot. Mediotergite brownish black. Pleuron of thorax (Fig. 1a) yellow, with a broad, darkbrown stripe extending from cervical region to mediotergite. Setae on thorax brownish black. Coxae pale yellow; trochanters pale yellow; femora brownish yellow, with fore femur paler; tibiae brownish yellow; tarsi brownish yellow, with terminal three segments darker. Setae on legs brownish black. Wing (Fig. 1d) tinged pale brownish with a brownish-black pattern: seven large spots on costal region; seams along cord, $\mathrm{m}-\mathrm{m}$ and basal section of $\mathrm{M}_{3}$; a spot at fork of Rs; a very light spot at sub-tip of $\mathrm{A}_{2}$. Veins brownish yellow, darker in clouded areas. Venation: Sc long, $\mathrm{Sc}_{1}$ ending near fork of $\mathrm{Rs}, \mathrm{Sc}_{2}$ at its tip; basal section of $\mathrm{CuA}_{1}$ nearly its length before fork of $\mathrm{M}$. Halter length 1.1-1.2 mm, pale yellow with base of stem dark brown.

Abdomen (Fig. 1a). Tergites brownish yellow with caudal halves dark brown. Sternites pale yellow. Setae on tergites brown and on sternites white.

Hypopygium (Fig. 2). Posterior margin of ninth tergite slightly emarginate. Gonocoxite slender with an elongate and blunt-apexed ventromesal lobe. Clasper of gonostylus arched at 2/3 of length, tip acute. Lobe of gonostylus large with an arched rostral prolongation armed with two basal spines arising from two tubercles. Paramere stout, wide at base, distal part trianglar. Aedeagus long, with two apical lobes.

Female. Body length 5.5-6.4 mm, wing length 5.0-5.8 mm, mouthparts length 2.0-2.5 mm. Similar to male, but tenth tergite (Fig. 1e) brown. Cercus brownish yellow with basal $1 / 2$ brown. Hypogynial valve brownish yellow with tip slightly darker, tip near $2 / 3$ way along cercus.

Type material. Holotype: male (QAU), China: Zhejiang, Suichang, Mount Jiulong, Luohanyuan (28 23'24"N, 118 51'00"E, 517 m), 2019.VII.26, Xingyang Qian. Paratypes: 10 males 5 females (QAU), same data as holotype. 1 female (QAU), Chi- 

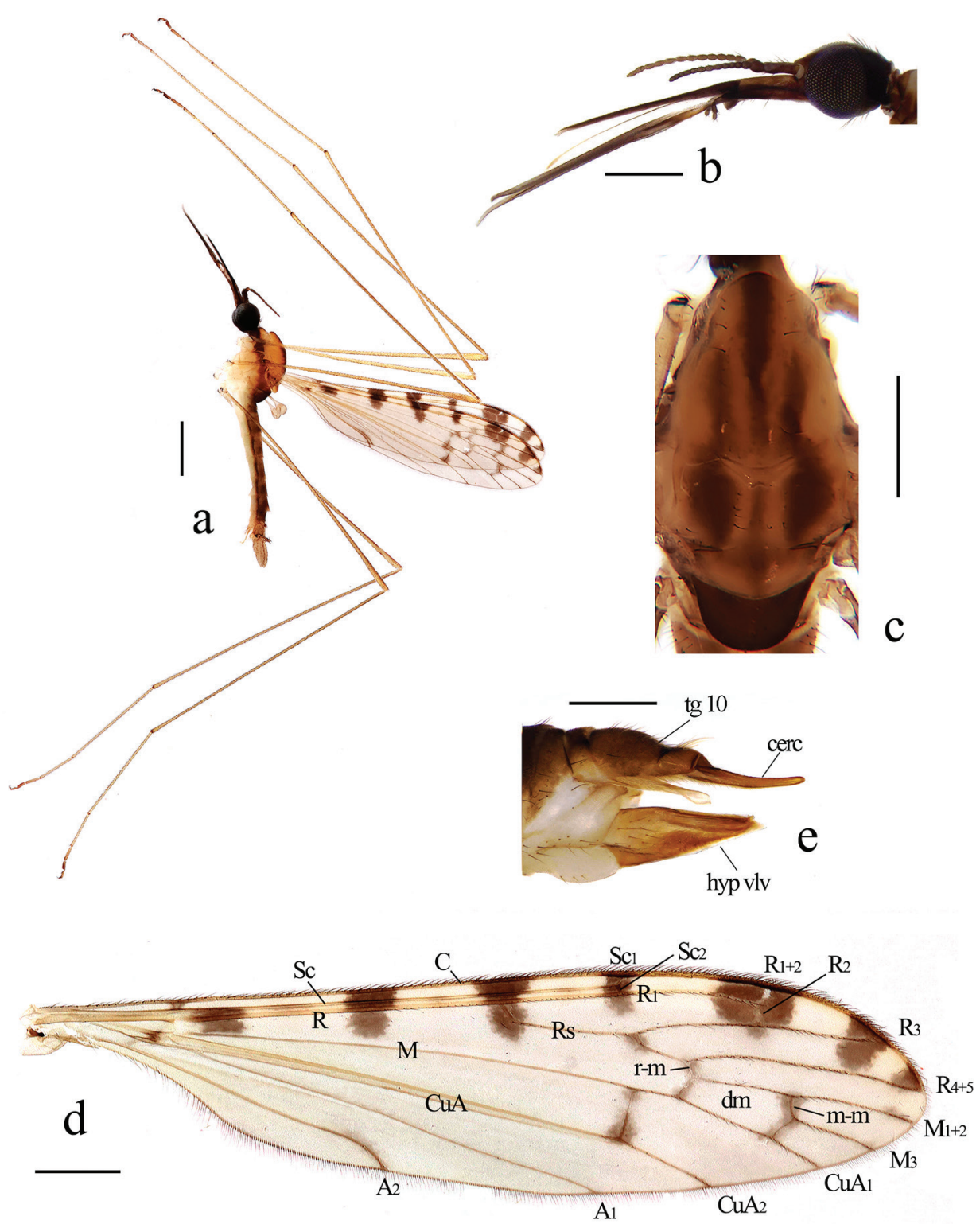

Figure I. Geranomyia jiulongensis sp. nov. a Male habitus, lateral view b head, lateral view c thorax, dorsal view d wing e ovipositor, lateral view. Scale bars: $1.0 \mathrm{~mm}(\mathbf{a}) ; 0.5 \mathrm{~mm}(\mathbf{b}-\mathbf{d}) ; 0.2 \mathrm{~mm}(\mathbf{e})$.

na: Zhejiang, Suichang, Mount Jiulong, Longkoucun $\left(28^{\circ} 18^{\prime} 11^{\prime \prime N}, 118^{\circ} 56^{\prime} 42^{\prime \prime E}\right.$, $305 \mathrm{~m}$ ), 2019.VII.24, Xingyang Qian. 1 male 5 females (QAU), China: Zhejiang,

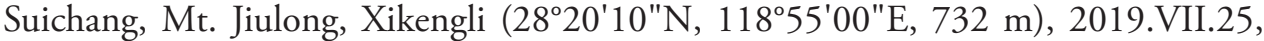
Xingyang Qian. 1 male (QAU), China: Zhejiang, Suichang, Mount Jiulong, Yanping $\left(28^{\circ} 22^{\prime} 23^{\prime \prime N}, 118^{\circ} 53^{\prime} 48^{\prime \prime E}, 667 \mathrm{~m}\right), 2019 . V I I .26$, Xingyang Qian. 1 female (QAU), 


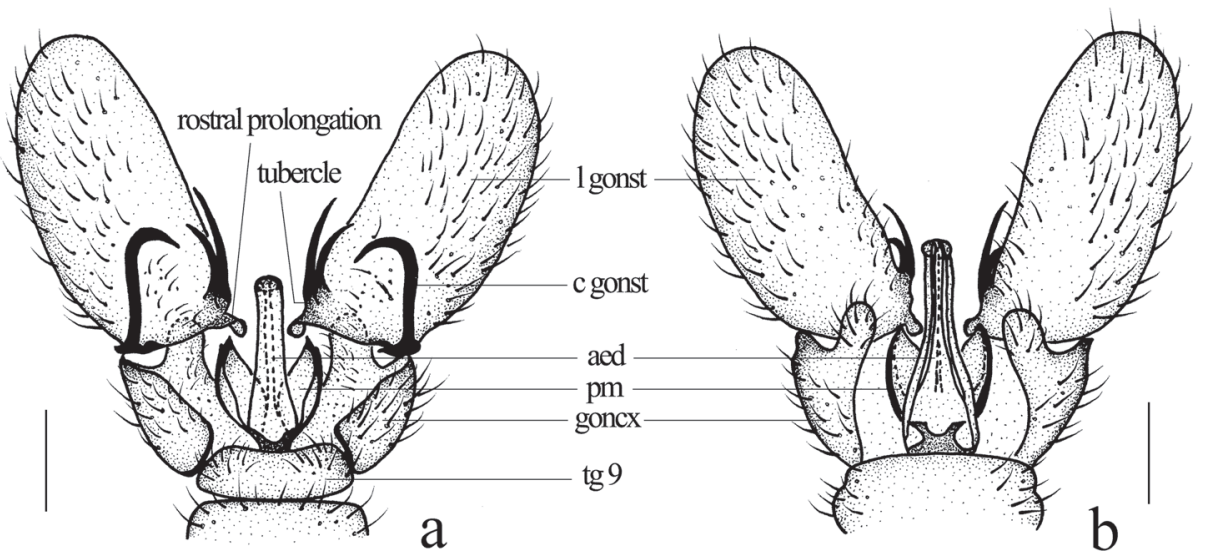

Figure 2. Geranomyia jiulongensis sp. nov. a male hypopygium, dorsal view $\mathbf{b}$ male hypopygium, ventral view. Scale bars: $0.2 \mathrm{~mm}$.

China: Zhejiang, Suichang, Mount Jiulong, Zuobieyuan $\left(28^{\circ} 17^{\prime} 10^{\prime \prime N}, 118^{\circ} 46^{\prime} 42^{\prime \prime} \mathrm{E}\right.$, $640 \mathrm{~m}), 2019$.VII.28, Xingyang Qian.

Distribution. China (Zhejiang).

Etymology. The species is named after the type locality, Mount Jiulong.

Remarks. This species is very similar to $G$. radialis but can be distinguished by the prescutum of the thorax having three broad, dark-brown stripes (Fig. 1c) and the lobe of the gonostylus being long and more than twice the length of the gonostylus clasper (Fig. 2a). In G. radialis, the prescutum has a narrow brown median stripe, and the lobe of the gonostylus is short and slightly exceeds the gonostylus clasper (Alexander 1930). This new species is also somewhat similar to G. immobilis (Alexander, 1932) from the Philippines in its pattern and wing venation but can be easily distinguished from it by the pleuron of the thorax being yellow with a broad dark brown stripe extending from the cervical region to the mediotergite (Fig. 1a) and the lobe of the gonostylus with two spines arising from two tubercles. In G. immobilis, the pleuron of the thorax is chiefly dark brown, with the sternopleurite light yellow, and the lobe of the gonostylus has two spines arising from a common tubercle (Alexander 1932).

\section{Geranomyia subablusa sp. nov.}

http://zoobank.org/2F4E8F84-2595-4B4C-9026-6ED380AA499D

Figures 3, 4

Diagnosis. Prescutum yellow with three broad, brown longitudinal stripes. Pleuron of thorax yellow, with a broad brown stripe. Wing with seven large spots on costal region, with second and third spots combined between $\mathrm{C}$ and $\mathrm{Sc} ; \mathrm{Sc}_{1}$ ending about $2 / 5$ of Rs; basal section of $\mathrm{CuA}_{1}$ more than $2 / 3$ of its own length before fork of $\mathrm{M}$. Lobe of gonostylus large with a large rostral prolongation armed with two 
long, slender spines, one arising from a large fleshy tubercle, other one directly arising from rostral prolongation.

Description. Male. Body length $6.2-6.5 \mathrm{~mm}$, wing length $6.0-6.3 \mathrm{~mm}$, mouthparts length 2.4-2.5 mm.

Head (Fig. 3b). Brownish black. Setae on head black. Antenna length 1.2-1.3 mm, dark brown. Scape cylindrical. Pedicel nearly globose. Flagellomeres oval, terminal flagellomere with tip knob-like. Mouthparts dark brown, with black setae.

Thorax (Fig. 3c). Pronotum brownish yellow, with a broad, dark-brown, median stripe. Prescutum yellow with three broad, brown, longitudinal stripes; each lateral stripe about 3/4 length of median stripe. Scutum pale yellow; each lobe with a large brown spot. Scutellum yellow, with brown sides; posterior region with a brown spot. Mediotergite dark brown. Pleuron of thorax (Fig. 3a) yellow, with a broad, brown stripe extending from cervical region to mediotergite. Setae on thorax brownish black. Coxae yellow; trochanters yellow; femora brownish yellow; tibiae brownish yellow; tarsi brownish yellow, with terminal three segments darker. Setae on legs brownish black. Wing (Fig. 3d) tinged with pale brownish with brownish black pattern: seven large spots on costal region, with second and third spots combined between $\mathrm{C}$ and Sc; seams along cord, $m-m$ and basal section of $M_{3}$; spots at fork of Rs and tip of $M_{1+2}, M_{3}, C u A_{1}$ and $A_{2}$; a very light and small spot at tip of $A_{1}$. Veins brownish yellow, darker in clouded areas. Venation: Sc long, $\mathrm{Sc}_{1}$ ending about $2 / 3$ of $\mathrm{Rs}, \mathrm{Sc}_{2}$ at its tip; basal section of $\mathrm{CuA}_{1}$ more than 2/3 of its own length before fork of $M$. Halter length 1.1-1.2 mm, yellowish white.

Abdomen (Fig. 3a). Tergites brown. Sternites pale yellow. Setae on tergites brown and on sternites white.

Hypopygium (Fig. 4). Posterior margin of ninth tergite emarginate. Gonocoxite stout with a blunt-apexed ventromesal lobe. Clasper of gonostylus arched at 2/3 of length, tip acute. Lobe of gonostylus large, with a large rostral prolongation armed with two long, slender spines, one arising from a large fleshy tubercle at sub-tip of rostral prolongation, other one directly arising from middle of rostral prolongation. Paramere slender, wide at base, distal part triangular. Aedeagus relatively long, with two apical lobes.

Female. Body length 6.0-7.0 mm, wing length 6.0-6.5 mm, mouthparts length 2.3-2.5 mm. Similar to male, but tenth tergite (Fig. 3e) brown, with tip brownish yellow. Cercus brownish yellow, with basal $1 / 2$ brown, long. Hypogynial valve brownish yellow, slender, and long, with tip near 2/3 way along cercus.

Type material. Holotype: male (QAU), China: Zhejiang, Suichang, Mount Jiulong, Luohanyuan (28²3'24"N, 11851'00"E, $517 \mathrm{~m}), 2019 . V I I .26$, Xingyang Qian. Paratypes: 4 males 10 females (QAU), same data as holotype. 2 males 2 females (QAU), China: Zhejiang, Suichang, Mount Jiulong, Longkoucun $\left(28^{\circ} 18^{\prime} 11^{\prime \prime} \mathrm{N}\right.$, 11856'42"E, 305 m), 2019.VII.24, Xingyang Qian.

Distribution. China (Zhejiang).

Etymology. The name of the new species refers to the $G$. ablusa (Alexander, 1967), as the two species are very similar morphologically.

Remarks. This species is very similar to $G$. ablusa from India but can be distinguished from it by the femora being uniformly brownish yellow (Fig. 3a), the yellowish 

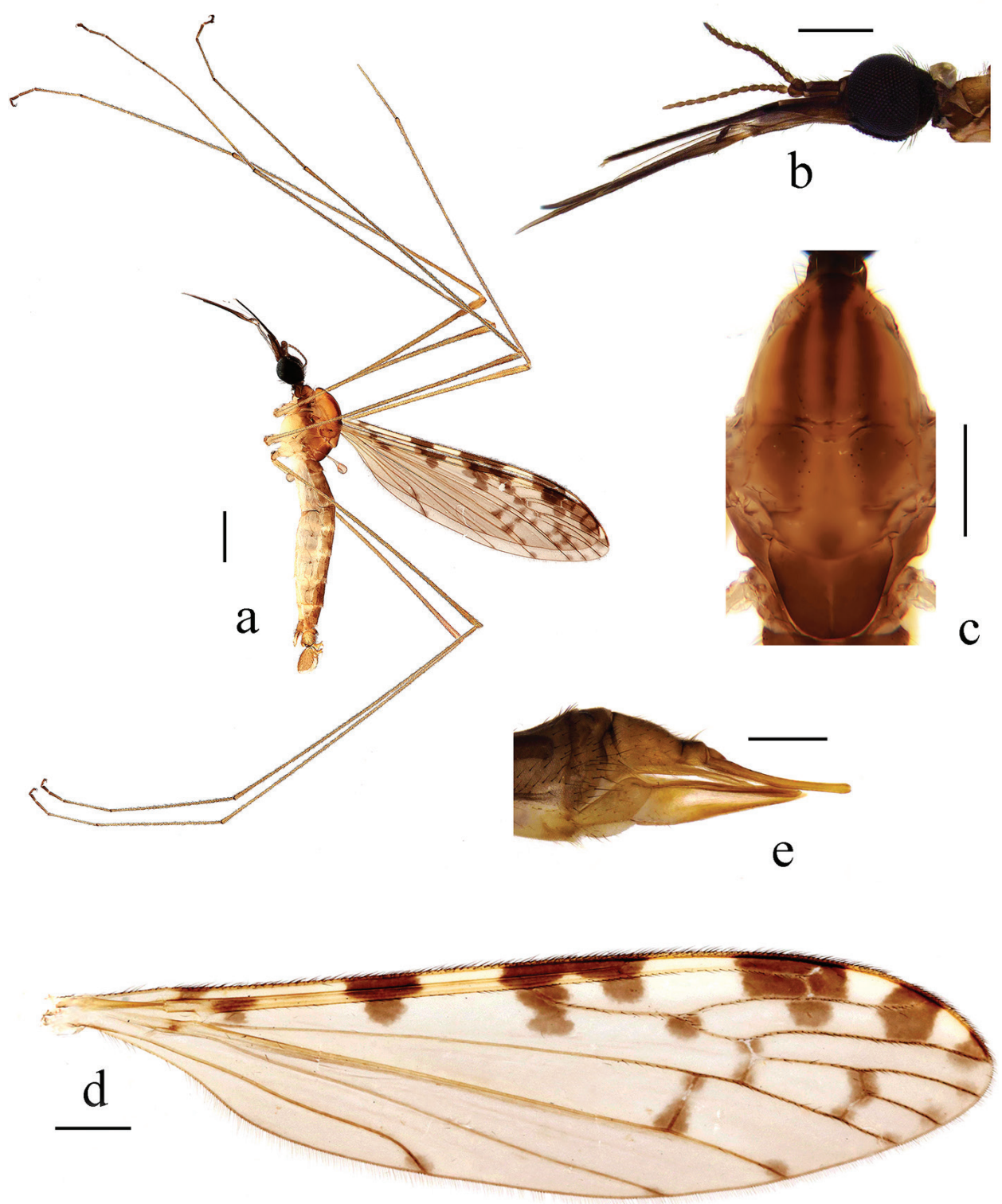

Figure 3. Geranomyia subablusa sp. nov. a Male habitus, lateral view $\mathbf{b}$ head, lateral view $\mathbf{c}$ thorax, dorsal view d wing e ovipositor, lateral view. Scale bars: $1.0 \mathrm{~mm}(\mathbf{a}) ; 0.5 \mathrm{~mm}(\mathbf{b}-\mathbf{d}) ; 0.2 \mathrm{~mm}(\mathbf{e})$.

white halter, and the aedeagus lacking genital openings near the apical lobes (Fig. 4b). In $G$. ablusa, the femora have vague, pale brown, subterminal rings, the halter is dark brown, and the aedeagus has the genital openings subterminal and lateral in position to the apical lobes (Alexander 1967c). 

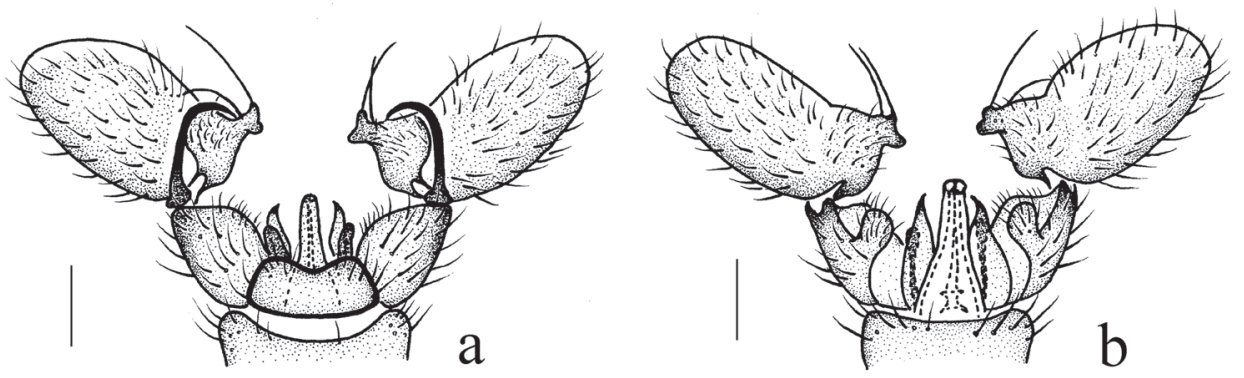

Figure 4. Geranomyia subablusa sp. nov. a male hypopygium, dorsal view $\mathbf{b}$ male hypopygium, ventral view. Scale bars: $0.2 \mathrm{~mm}$.

\section{Geranomyia nigra Zhang, Zhang \& Yang, 2016}

Geranomyia nigra: Zhang et al. 2016: 150. Type locality: Fuxing, Taoyuan, Taiwan (China).

Specimens examined. Holotype: male (CAU), China: Taiwan, Taoyuan, Fuxing $\left(24^{\circ} 48^{\prime} 36^{\prime \prime N}, 121^{\circ} 20^{\prime} 55^{\prime \prime E}, 420 \mathrm{~m}\right), 2013 . V I .10$, Wenliang Li (light trap). Other material: 2 males 2 females (QAU), China: Zhejiang, Suichang, Mount Jiulong, Luohanyuan (28²3'24"N, 11851'00"E, 517 m), 2019.VII.26, Xingyang Qian. 1 male 2 females (QAU), China: Zhejiang, Suichang, Mount Jiulong, Longkoucun (2818'11"N, 11856'42"E, 305 m), 2019.VII.24, Xingyang Qian.

Distribution. China (Gansu, Sichuan, Yunnan, Zhejiang, Guangxi, Taiwan).

\section{Geranomyia suensoniana (Alexander, 1929)}

Limonia (Geranomyia) suensoniana: Alexander 1929a: 330. Type locality: hills south of Ningbo, Zhejiang (China).

Specimens examined. Holotype: male (USNM), China: Zhejiang, hills south of Ningbo, 1925.V.1, E. Suenson. Other material: 2 male 4 females (QAU), China: Zhejiang, Suichang, Mount Jiulong, Luohanyuan $\left(28^{\circ} 23^{\prime} 24^{\prime \prime N}, 118^{\circ} 51^{\prime} 00^{\prime \prime E}, 517\right.$ m), 2019.VII.26, Xingyang Qian.

Distribution. China (Zhejiang).

\section{Acknowledgements}

We are very grateful to Jon K. Gelhaus, Sigitas Podenas, David G. Furth, Yan Li, and Qifei Liu for their great help with the study of type material from the USNM, and to 
Duncan Sivell and Jinlong Ren for assistance in the study of type material from the NHM. We express our sincere thanks to Ali M. Yasir for revising the manuscript. We also express our sincere thanks to Zehui Kang and Ding Yang for their great help during the study. This work was funded by the Project Study on Biodiversity of the Superfamily Tipuloidea from Shandong Province and the Project Study on Systematics of the Family Blephariceridae from China supported by Shandong Provincial Natural Science Foundation (ZR2018LC006, ZR2019BC034), and the Project Species Diversity and Geographical Distribution Patterns of Ptychopteridae in China supported by National Natural Science Foundation of China (41901061). This work was also supported by grants from the High-level Talents Fund of Qingdao Agricultural University, China (663-1118015).

\section{References}

Alexander CP (1916) New or little-known crane-flies from the United States and Canada: Tipulidae, Ptychopteridae, Diptera. Part 3. Proceedings of the Academy of Natural Sciences of Philadelphia 68: 486-549.

Alexander CP (1919) The crane-flies of New York. Part I. Distribution and taxonomy of the adult flies. Memoirs, Cornell University Agricultural Experiment Station 25: 767-993.

Alexander CP (1920) The crane-flies of New York. Part II. Biology and phylogeny. Memoirs, Cornell University Agricultural Experiment Station 38: 691-1133. https://doi. org/10.5962/bhl.title.33641

Alexander CP (1928a) Studies on the crane-flies of Mexico. Part IV. (Order Diptera, Superfamily Tipuloidea). Annals of the Entomological Society of America 21: 101-119. https:// doi.org/10.1093/aesa/21.1.101

Alexander CP (1928b) New or little-known Tipulidae (Diptera). XXXIX. Australasian species. Annals and Magazine of Natural History (Series 10) 1: 577-601. https://doi. org/10.1080/00222932808672824

Alexander CP (1929a) New or little-known Tipulidae from eastern Asia (Diptera). IV. Philippine Journal of Science 40: 317-348.

Alexander CP (1929b) New or little-known Tipulidae from the Philippines (Diptera). V. Philippine Journal of Science 40: 239-273.

Alexander CP (1930a) New or little-known Tipulidae from eastern Asia (Diptera). VI. Philippine Journal of Science 42: 59-83.

Alexander CP (1930b) New or little-known Tipulidae from eastern Asia (Diptera). VIII. Philippine Journal of Science 43: 507-536.

Alexander CP (1931) Deutsche Limnologische Sunda-Expedition. The crane-flies (Tipulidae, Diptera). Archiv fur Hydrobiologie, Suppl.-Bd 9 (Tropische Binnengewasser, Band 2): 135-191.

Alexander CP (1932) New or little-known Tipulidae from the Philippines (Diptera). XV. Philippine Journal of Science 48: 597-638.

Alexander CP (1933) New or little-known Tipulidae from eastern Asia (Diptera). XII. Philippine Journal of Science 50: 129-162.

Alexander CP (1934) New or little-known Tipulidae from eastern Asia (Diptera). XVIII. Philippine Journal of Science 53: 267-300. 
Alexander CP (1937a) New or little-known Tipulidae from eastern Asia (Diptera). XXXV. Philippine Journal of Science 63: 365-404.

Alexander CP (1937b) New or little-known Tipulidae from eastern China. Part II. Notes d'Entomologie Chinoise 4: 65-88.

Alexander CP (1940) New or little-known Tipulidae from eastern Asia (Diptera). XLII. Philippine Journal of Science 71: 169-204.

Alexander CP (1948) Records and descriptions of North American crane-flies (Diptera). Part VII. The Tipuloidea of Utah. I. American Midland Naturalist 39: 1-82. https://doi. org/10.2307/2421428

Alexander CP (1954) An undescribed crane-fly from the Hawaiian Islands (Diptera: Tipulidae). Proceedings of the Hawaiian Entomological Society 15: 297-298.

Alexander CP (1964) Diptera (Nematocera): Tanyderidae, Ptychopteridae, Tipulidae. South African Animal Life 10: 229-441.

Alexander CP (1967a) Notes on the tropical American species of Tipulidae (Diptera). VII. The tribe Limoniini, genus Limonia, concluded; Helius, Orimarga, and others; tribe Pediciini; subfamily Cylindrotominae. Studia Entomologica, New Series 10: 277-352.

Alexander CP (1967b) The crane flies of California. Bulletin of the California Insect Survey 8: $1-263$.

Alexander CP (1967c) New or little-known Tipulidae from eastern Asia (Diptera). LX. Philippine Journal of Science 95: 227-266.

Alexander CP (1970a) Bredin-Archbold-Smithsonian biological survey of Dominica. The crane flies (Diptera: Tipulidae). Smithsonian Contributions to Zoology 45: 1-59. https:// doi.org/10.5479/si.00810282.45

Alexander CP (1970b) An undescribed species of Orimarga from Israel (Tipulidae: Diptera). Bonner Zoologische Beiträge 21: 145-148.

Alexander CP, Byers GW (1981) Tipulidae. In: McAlpine JF, Peterson BV, Shewell GE, Teskey HJ, Vockeroth JR, Wood DM (Eds) Manual of Nearctic Diptera. Vol. I. Biosystematic Research Centre, Ottawa, Ontario, 153-190.

Alexander CP, Malloch JR (1920) Notes on the life-history of a crane-fly of the genus Geranomyia Haliday (Tipulidae, Diptera). Transactions of the Illinois State Academy of Science 13: 310-319.

Bangerter H (1929) Mucken-Metamorphosen. II. Konowia 8: 1-7.

Edwards FW (1911) On some Tipulidae (Limoniinae) from Ceylon in the British Museum collection, with descriptions of eight new species. Annals and Magazine of Natural History (Series 8) 8: 58-67. https://doi.org/10.1080/00222931108693000

Edwards FW (1913) Tipulidae and Culicidae from the Lake of Tiberias and Damascus. Journal and Proceedings of the Asiatic Society of Bengal (N.S.) 9: 47-51.

Edwards FW (1916) Newandlittle-known Tipulidae, chiefly from Formosa. Annalsand Magazine of Natural History (Series 8) 18: 245-269. https://doi.org/10.1080/00222931608693846

Edwards FW (1921) New and little-known Tipulidae, chiefly from Formosa. Part II. Annals and Magazine of Natural History (Series 9) 8: 99-115. https://doi. org/10.1080/00222932108632560

Englund RA (1999) New records and range extensions of native Odonata (Coenagrionidae) and introduced aquatic species in the Hawaiian Islands. In: Evenhuis NL, Eldredge LG 
(Eds) Records of the Hawaii Biological Survey for 1998. Part 2: notes. Bishop Museum Occasional Papers 59: 15-19.

Haliday AH (1833) Catalogue of the Diptera occurring about Holywood in Downshire. Entomological Magazine, London 1: 147-180.

Harrison AD, Barnard KH (1972) The stream fauna of an isolated mountain massif; Table Mountain, Cape Town, South Africa. Transactions of the Royal Society of South Africa 40: 135-153. https://doi.org/10.1080/00359197209519414

Knab F (1910) The feeding habits of Geranomyia. Proceedings of the Entomological Society of Washington 12: 61-65.

McAlpine JF (1981) Morphology and terminology, Adults. In: McAlpine JF, Peterson BV, Shewell GE, Teskey HJ, Vockeroth JR, Wood DM (Eds) Manual of Nearctic Diptera. Vol. I. Biosystematic Research Centre, Ottawa, Ontario, 9-63.

Meijere JCH de (1911) Studien über Südostasiatische Dipteren, 5. Ostindische Tipulidae. Tijdschrift voor Entomologie 54: 21-79. https://doi.org/10.5962/bhl.title.8578

Mik J (1867) Dipterologische Beiträge zur Fauna austriaca. Verhandlungen der ZoologischBotanischen Gesellschaft in Wien 17: 413-423.

Oosterbroek P (2020) Catalogue of the Craneflies of the World (Diptera, Tipuloidea, Pediciidae, Limoniidae, Cylindrotomidae, Tipulidae). http://ccw.naturalis.nl/ [Accessed on 2020-6-24]

Osten Sacken CR (1860) New genera and species of North American Tipulidae with short palpi, with an attempt at a new classification of the tribe. Proceedings of the Academy of Natural Sciences of Philadelphia 1859: 197-256.

Osten Sacken CR (1869) Monographs of the Diptera of North America. Part IV. Smithsonian Miscellaneous Collections 8 (219): 1-345.

Ribeiro GC (2006) Homology of the gonostylus in crane flies, with emphasis on the families Tipulidae and Limoniidae (Diptera, Tipulomorpha). Zootaxa 1110: 47-57. https://doi. org/10.11646/zootaxa.1110.1.5

Rogers JS (1927) Notes on the biology of Atarba picticornis Osten Sacken. Tipulidae-Diptera. Florida Entomologist 10: 49-55. https://doi.org/10.2307/3492493

Rogers JS (1930) The summer crane-fly fauna of the Cumberland Plateau in Tennessee. Occasional Papers of the Museum of Zoology, University of Michigan 215: 1-50.

Say T (1823) Descriptions of dipterous insects of the United States. Journal of the Academy of Natural Sciences of Philadelphia 3: 9-54, 73-104.

Westwood JO (1836) Insectorum nonnullorum novorum (ex ordine Dipterorum) descriptiones. Annales de la Société Entomologique de France 4(1): 681-685.

Young CW (1978) Comparison of the crane flies (Diptera: Tipulidae) of two woodlands in eastern Kansas, with a key to the adult crane flies of eastern Kansas. Kansas University Science Bulletin 51: 407-440. https://doi.org/10.5962/bhl.part.17243

Young CW, Gelhaus JK (2000) Crane Flies of Pennsylvania: Preliminary checklist and database development with emphasis on aquatic species. Report submitted to Pennsylvania Wild Resource Conservation Fund and PA Fish \& Boat Commission, Harrisburg \& Bellefonte, Pennsylvania, 256 pp.

Zhang X, Zhang Z, Yang D (2016) Five new species of Geranomyia Haliday, 1833 (Diptera, Limoniidae) from China. Zootaxa 4154(2): 139-154. https://doi.org/10.11646/ zootaxa.4154.2.2 